\title{
Auto-transplantation of teeth: Our Experience
}

\author{
Ashutosh Kumar Singh ${ }^{1}$, Lipika Shrestha ${ }^{2}$ \\ ${ }^{1}$ Lecturer,Department of Oral \& maxillofacial surgery, ${ }^{2}$ Assistant Professor, Department of Conservative \\ Dentistry and Endodontics, College of Medical Sciences, Bharatpur, Chitwan
}

\section{Correspondence}

Dr. Ashutosh Kumar Singh

Department Department of

Oral \& maxillofacial surgery,

COMS, Bharatpur, Nepal

Email:

drashutoshkumarsingh@gmail

.com

DOI: http://

dx.doi.org/10.3126/

jemsn.v12i3.15978

Article received: August

20th, 2016

Article accepted: September

29th, 2016

\begin{abstract}
Background \& Objectives: To evaluate success rate of autotransplantation of teeth with immature and mature root apex. Materials \& Methods: Fifteen consecutively auto-transplanted teeth ( six with immature apex and nine with mature apex ) were followed up for a mean duration of 8.6 months and assessed for post transplant mobility, root resorption, root growth and pain. The transplanted teeth were assessed clinically and Intraoral periapical radiographs (IOPAR) were taken every three months. Results: Overall success rate was $73.3 \%$. Higher success rate was observed for teeth with immature apex as compared to teeth with mature apex. Conclusion: Auto-transplantation can be used as reliable method for replacement of missing teeth if proper case selection and surgical protocol is followed.
\end{abstract}

Key words: Auto-transplantation; teeth; root growth; root resorption

Citation: Singh AK, Shrestha L. Auto-transplantation of teeth: Our Experience. JCMS Nepal. 2016;12(3):99 $-102$.

\section{INTRODUCTION}

Hypodontia is common manifestation of various conditions like oral diseases (caries and periodontal disease), majority of cases of maxillofacial trauma, developmental anomalies and hereditary conditions like ectodermal dysplasia. Evolutions in material science and operative techniques have provided various possibilities like dentures, fixed bridges and implants for replacement of missing tooth with optimum aesthetics and function. However each method comes with limitations of its own and new methods are being perfected to address these limitations.

Autotransplantation of tooth can be defined as surgical relocation of a tooth from one position to other in same individual. ${ }^{1}$ The origin of transplantation of tooth can be traced back to the Egyptian civilisation when allotransplants from slaves were used in Pharaohs. ${ }^{2}$ This method carried the risk of transfer of infection from donor to recipient and had very limited success due to immunogenic reactions. Auto-transplantation of teeth was described first by Swedish dentist Vidman in $1915^{3}$ and major principles were laid down by M.L. Hale in $1954 .{ }^{2}$ Autotransplant is the treatment of choice for replacement of missing teeth in growing and adolescent child where use of implant is contraindicated due to inference with growth of alveolar process and there are also situation in adult patient where autotransplantation is suitable alternative to regular procedures. ${ }^{2}$ Various clinical trials have indicated that successfully transplanted teeth function as totally normal teeth, ensures that alveolar bone volume is maintained, offers improved aesthetics, arch form, dentofacial development, mastication, speech and arch integrity and unlike restorative prosthetic units, also provide proprioception during function. ${ }^{4}$ This technique is also economical as compared to other prosthetic/ restorative and orthodontic treatment options.

In the 1950s success rate of autotransplantation was approximately $50 \%$ because of the difficulty in 
predicting root development after transplantation and dental root resorption teeth, hence the procedure was used infrequently. ${ }^{5}$ In recent years great strides have been made in understanding of wound healing, healing of periodontal tissues and dental root resorption, and the transplant success rate has increased rapidly, leading to new clinical interest. Tsukiboshi ${ }^{6}$ had reported a $90 \%$ survival rate and an $82 \%$ success rate for 250 cases observed for 6 years. Czochrowska et $\mathrm{al}^{7}$ have reported yield survival rate of $90 \%$ and success rate of $79 \%$ in 33 transplanted teeth in the mean observation period of 26.5 years. Lundberg and Isaksson ${ }^{8}$ reported a $94 \%$ success rate in cases with incompletely formed roots and $84 \%$ in cases with completely formed roots and a higher success rate in cases with immature teeth.

\section{MATERIALS AND METHODS}

This prospective study was conducted at dental college and hospital in central Nepal. Fifteen patients consecutively treated with auto-transplation between June 2014 -January 2015 were followed up for a mean duration of 8.6 months (6-12 months). The study sample consisted of six growing subjects and nine adult subjects which were selected on the basis of following inclusion criteria: a) Subjects without any systemic or local health conditions which would contraindicate surgical procedures b) Subjects with grossly decayed or fractured first molar which was indicated for extraction c) Subjects with healthy third molar in the same arch showing good morphology.

Prior to transplantation, clinical and radiographic examinations of the donor and recipient sites were normally performed. Intraoral radiographs were used for assessment of the stage of root development of the donor tooth. Examination of these radiographs provided information about the tooth's size, shape, and root length, as well as about the surrounding periodontal structures. The mesiodistal dimensions of the donor tooth and of the recipient area was measured on periapical radiographs taken with the parallel technique.

Surgical technique:

After using appropriate local anesthesia, the recipient site was prepared with surgical round bur. The donor tooth was extracted as atraumatically as possible. The size of recipient socket was adjusted based on root morphology of donor tooth. For patients with closed apex, in vitro root canal treatment was done prior to transplantation.
Stabilization was achieved using a $0.017 \times 0.025$ " stainless steel wire and 3-0 nylon sutures. The enamel on the buccal surfaces of the autotransplanted third molar and adjacent tooth was etched with $37 \%$ phosphoric acid for 30 seconds. Stainless steel wire was fixed on the etched enamel with light-cured composite resin. Since only one tooth was used for stabilization, the temporary fixation had semi-rigid characteristics and the autotransplanted tooth remained splinted for two weeks. The transplanted teeth was secured with rigid splinting using orthodontic wires and light cure composite. The auto-transplanted tooth were placed in slight infraocclusion and patient were advised to avoid chewing hard food from the same side till the tooth remain splinted. Post surgical medications were antibiotic (Amoxycillin $-500 \mathrm{mg}$ -tds) and analgesics. After two weeks the splinting was removed and patient were recalled for follow up after one month and then after

In each follow up visit, transplanted tooth was assessed for:

a. Mobility: Grade-I slightly more than normal, grade II: moderately more than normal, and grade III: severe mobility faciolingually and mesiodistally combined with vertical displacement b. No discomfort or pain and a normal periodontal probing

c. Radiographic: IOPAR was used for assessment of root resorption periodontal ligament space and lamina dura.

Prosthodontic treatment, if required, was performed after 6 months of transplantation. The transplanted teeth were assessed at two weeks after removal of splint, three months, six months, nine months and 12 months. IOPAR of transplanted teeth was obtained at three months, six months, nine months and twelve months. Subjects were advised to report to OPD if they noticed any pain, tenderness or excessive mobility.

\section{RESULTS}

The demographic characteristics of subjects is mentioned in table 1. On first post transplant evaluation carried at two weeks all the teeth with incomplete root formation showed grade III mobility while all but one case with completed root showed grade II mobility. In subjects with immature apex splinting was continued for further one week while in cases with completed root the splint was removed. None of the cases showed marked pain or tenderness. Signs of inflammation were still present in gingiva surrounding 
Table 1: Demographic characteristics

\begin{tabular}{llll}
$\begin{array}{l}\text { Type of } \\
\text { root }\end{array}$ & Male & Female & $\begin{array}{l}\text { Mean age } \pm \\
\text { SD (Yrs) }\end{array}$ \\
\hline Immature & 2 & 4 & $17 \pm 0.89$ \\
\hline Completed & 4 & 5 & $29.5 \pm 3.5$ \\
\hline Total $(15)$ & 6 & 9 & $24.5 \mathrm{y} \pm 6.9$
\end{tabular}

transplanted teeth. At three months, the gingiva surrounding the transplanted teeth was similar to the adjacent tooth and mobility of all teeth with immature apex has reduced to grade II while teeth with closed apex showed grade I mobility. In one case with immature apex, signs of pulp necrosis and associated root resorption was seen.

At six months mobility has reduced to grade I in all cases except one case with immature apex which showed arrested root development however it stabilised and root formation appeared normal at one year follow up. Pulp necrosis with signs of periapical radiolucency was seen in one case with immature apex. Surface and inflammatory root resorption was observed in two cases with complete root apex while replacement resorption was observed in one case with completed root formation.

Overall, eleven cases out of fifteen $(73.33 \%)$ were stable at the last follow-up and didn't show any sign of pain, inflammation or root resorption and considered successful transplant.

\section{DISCUSSION}

In recent years, auto-transplantation procedure has emerged as reliable alternative for replacement of missing teeth.. Since the 1990s, many studies have examined the healing of periodontal tissues and periodontal membrane and dental root resorption, and the transplant success rate increased rapidly, drawing new clinical interest. ${ }^{6,7,8}$

In our study the overall success rate of transplanted teeth is $73.3 \%$ however success rate for subjects with incomplete root formation was $80 \%$ and that for completed root formation was $66.6 \%$. Previous studies have reported a wide range of success rate for transplanted teeth ranging from 64 to $100 \%{ }^{9}$ This excellent outcome in results published in literature may be result of publication bias because studies with lower success rate failed to get published. The existing database point out that several factors can affect the prognosis of auto- transplantation procedure which include the root completion stage of transplant teeth, atraumatic surgery, preservation of periodontium , optimal fixation and prevention of infection however the most important predictor of success and survival is the stage of the root development of the donor tooth at the moment of transplantation. ${ }^{1,2,6,8}$ In our study $60 \%$ of the total transplants had closed apex out of which $33.3 \%$ were lost as compared to $16.6 \%$ lost for samples with immature apex and developing root. Lundberg and Isaksson reported a 94\% success rate in cases with incompletely formed roots and $84 \%$ in cases with completely formed root. Similar findings have been reported by Schwarth et al. ${ }^{10}$ However, based on data published recently, the success rate of autotransplantation of teeth with complete root formations has been higher. ${ }^{11,12,13}$ This conflicting result may be due to variation in surgical skill, type of transplant, methods of splinting condition of recipient site etc. Another factor which is important of success of transplant is vitality of periodontal ligament (PDL). ${ }^{5}$ The chance of PDL survival is inversely proportional to extraoral dry time. Previous studies have reported that vitality of PDL decreases rapidly if extraoral dry time is more than eighteen minutes. ${ }^{14,15}$ In our study, endodontic treatment was done in cases with closed apex. To protect the vitality of PDL, endodontic treatment was done by keeping the teeth wrapped in wet saline gauze. The main focus was to remove the pulp only, so as to keep extraoral time as low as possible however this may have affected the survival rate for these teeth. In our study rigid fixation with orthodontic wires was used to fix the transplant teeth. The duration of fixation was two to three weeks and fixation was removed once the vertical mobility was reduced. Tsukiboshi et $\mathrm{al}^{16}$ reported that the tooth should be fixed for between two weeks and two months depending on whether the mobility is reduced.Some authors have recommended non-rigid fixation for higher survival rates but in lack of comparative study ,no direct comparison can be made between rigid and non-rigid method of fixation. ${ }^{17,18}$

\section{CONCLUSION}

Auto-transplantation has high success rate if surgical protocols are followed and careful selection of transplant and donor site is done. Success rate is higher for teeth with immature apex however studies with long term follow-ups and large study samples are required to reach a definite conclusion. 
REFERENCES

1. Machado LA, do Nascimento RR, Ferreira DM, Mattos $\mathrm{CT}$, Vilella OV. Long-term prognosis of tooth autotransplantation: a systematic review and meta-analysis. Int J Oral Maxillofac Surg. 2016 May;45(5):610-7. DOI: 10.1016/j.ijom.2015.11.010. PMID: 26696138.

2. Cohen AS, Shen TC, Pogrel MA. Transplanting teeth successfully: autografts and allografts that work. JADA. 1995;126(4):481-5. DOI: 10.14219/ jada.archive.1995.0211.

3. Tsukiboshi M. Autogenous tooth transplantation: A reevaluation. Int J Periodontics Restorative Dent 1993;13:120-49. PMID: 8360005.

4. Almpani, K, Papageorgiou, SN, Papadopoulos MA. Autotransplantation of teeth in humans: a systematic review and meta-analysis. Clin Oral Investig. $2015 \mathrm{Jul} ; 19$ (6):1157-79. doi: 10.1007/s00784-015-1473-9. PMID: 25903060 .

5. Bae JH, Choi YH, Cho BH, Kim YK, Kim SG. Autotransplantation of teeth with complete root formation: a case series. J Endod. 2010 Aug;36(8):1422-6. DOI: 10.1016/j.joen.2010.04.028. PMID: 20647110.

6. Tsukiboshi M. Autotransplantation of teeth: requirements for predictable success. Dent Traumatol. 2002;18:157-80. DOI: 10.1034/j.1600-9657.2002.00118.x. PMID:12442825.

7. Czochrowska EM, Stenvik A, Bjercke B, Zachrisson BU. Outcome of tooth transplantation: survival and success rates 17-41 years posttreatment. Am J Orthod Dentofacial Orthop. 2002 Feb;121(2):110-9. PMID: 11840123.

8. Lundberg T, Isaksson S. A clinical follow-up study of 278 autotransplanted teeth. Br J Oral Maxillofac Surg 1996;34:181-5. DOI: 10.1016/S0266-4356(96)90374-5

9. Verweij JP, Toxopeus EE, Fiocco M, Mensink G, van Merkesteyn JPR. Success and survival of autotransplanted premolars and molars during short-term clinical follow-up. J Clin Periodontol. 2015. doi: 10.1111/jepe. 12492

10. Schwartz O, Bergmann P, Klausen B. Autotransplantation of human teeth. A life-table analysis of prognostic factors. Int J Oral Surg 1985;14:245-58. DOI: 10.1016/S0300-9785 (85)80036-3.

11. Akkocaoglu M, Kasaboglu O. Success rate of autotransplanted teeth without stabilisation by splints: a long-term clinical and radiological follow-up. Br J Oral Maxillofac Surg. 2005;43:31-5. DOI: 10.1016/ j.bjoms.2004.08.010. PMID:15620771

12. Kristerson L, Johansson LA, Kisch J, Stadler LE. Autotransplantation of third molars as treatment in advanced periodontal disease. J Clin Periodontol. 1991;18:521-8. DOI: 10.1111/j.1600051X.1991.tb00084.x. PMID:1894746.

13. Waikakul A, Kasetsuwan J, Punwutikorn J. Response of autotransplanted teeth to electric pulp testing. Oral Surg Oral Med Oral Pathol Oral Radiol Endod. 2002;94:249-55. 10.1067/moe.2002.126162. PMID:12221395.

14. Andreasen JO. Effect of extra-alveolar period and storage media upon periodontal and pulpal healing after replantation of mature permanent incisors in monkeys. Int J Oral Surg. 1981;10:43-53. DOI: 10.1016/S0300-9785(81) 80007-5.

15. Andreasen JO. Periodontal healing after replantation and autotransplantation of incisors in monkeys. Int J Oral Surg. 1981;10:54-6. PMID: 6792095.

16. Tsukiboshi M, Andreasen J, Asai Y. Autotransplantation of teeth. Chicago; Quintessence, 2001:10-4, 97, 152-67.

17. Kristerson L, Andreasen JO. The effect of splinting upon periodontal and pulpal healing after autotransplantation of mature and immature permanent incisors in monkeys. Int J Oral Surg. 1983 Aug; 12(4):239-49.

18. Oskar Bauss, Reinhard Schilke, Christian Fenske, Werner Engelke, Stavros Kiliaridis. Autotransplantation of immature third molars: influence of different splinting methods and fixation periods. Dental Traumatology, 18: $322-8$. 